\title{
Knowledge and Myths about Preeclampsia and Eclampsia and its influence on Antenatal Service Utilization among Expecting Couples in Mtwara Regional: A Cross Sectional Analytical Study.
}

\section{Aziza Shaibu Machenje ( $\nabla$ gmachenje2@gmail.com )}

The University of Dodoma College of Health Sciences https://orcid.org/0000-0001-8210-226X

Stephen M. Kibusi

The University of Dodoma College of Health Sciences

Nyasiro Gibore

The University of Dodoma College of Health Sciences

Athanase Lilungulu

The University of Dodoma College of Health Sciences

Fabiola V. Moshi

The University of Dodoma College of Health Sciences

\section{Research article}

Keywords: Myths, expecting couples, ANC utilization, preeclampsia, eclampsia

Posted Date: June 8th, 2020

DOI: https://doi.org/10.21203/rs.3.rs-32334/v1

License: (a) (i) This work is licensed under a Creative Commons Attribution 4.0 International License.

Read Full License 


\section{Abstract}

Background: Hypertensive disorders of pregnancy, including preeclampsia and eclampsia are the major health problem and the main cause of the maternal and perinatal morbidity and mortality in Tanzania. The aim of this study was to assess knowledge and myths about preeclampsia and eclampsia and its influence in Antenatal Clinics (ANC) utilization among expecting couples in Mtwara region.

Method : A community based cross-sectional analytical study conducted in Mtwara Region, a random sampling procedure was employed to obtain a sample size of 384 couples with a total of 768 participants (male=384 and female $=384$ ). Interviewer structured questionnaire was used for data collection and Statistical package for social science (SPSS v.20) software was used for data entry and analysis. Descriptive statistics, cross tabulation, Principal component analysis (PCA) was conducted and inferential statistics were used to test association between variables obtained.

Results: Among 768 participants, only 292(38\%) had adequate knowledge about preeclampsia and eclampsia. More than a half $396(51.6 \%)$ of study respondents had weak myths while $372(48.4 \%)$ had strong myths on pre-eclampsia and eclampsia. Furthermore 492(64\%) had adequate antenatal care utilization. Study participants who had adequate knowledge on pre-eclampsia and eclampsia were almost 3 times more likely to utilize antenatal care services $(A O R=2.827 ; \mathrm{Cl}=1.719-4.651 ; p<0.001)$. Study participants who had weak myth on pre-eclampsia and eclampsia were less likely to have adequate antenatal care attendance $(A O R=0.370 ; C l=0.0229-0.599 ; p<0.001)$

Conclusion : The overall knowledge of preeclampsia and eclampsia was low. Majority of the female had adequate antenatal service utilization. Majority of respondents had weak myths. Government and stakeholders should ensure that community is equipped with knowledge about preeclampsia and eclampsia and the available Myths should be dispelled.

\section{Plain English}

One of the parameters which is monitored during antenatal visits is pregnant women's blood pressure. The blood pressure recorded during the first visit is used as an indicator of increased blood pressure. Preeclampsia is a condition in pregnancy characterized by high blood pressure, sometimes with fluid retention and protein in urine. Eclampsia is a severe condition of preeclampsia in which one or more convulsions occur in a pregnant suffering from high blood pressure, often followed by coma and posing a threat to the health of mother and baby.

The study aimed to find out the relationship between knowledge on preeclampsia and eclampsia on antenatal attendance among expecting couples in low resources setting of Mtwara Region Tanzania. The study was done among community with high prevalence of eclampsia. The reported cases of eclampsia mean that pregnant women's blood pressure is not well monitored. One expects the signs and symptoms of preeclampsia to be diagnosed during antenatal visits and proper management to be initiated so that it 
won't develop into a serious condition (eclampsia). The only window for monitoring the blood pressure is antenatal attendance.

The study also worked out the influence of knowledge and myth about preeclampsia and eclampsia on antenatal attendance. The local beliefs on the causes of preeclampsia and eclampsia may influence the use of health facility for management. If couples believe preeclampsia and eclampsia are caused by evil spirits, it is obvious the intervention will focus on traditional healers.

\section{Introduction}

Globally the Millennium development goals report shows that from 1990 to 2013 there was a decline of maternal deaths by $45 \%(289,000)$ per year[1]. However about 830 women died every day due to pregnancy complications or during delivery in 2015, meanwhile, perinatal mortality accounts for $40 \%$ of infants globally[2]. So far, in Sub-Sahara 179000 women die each year during pregnancy and childbirth[1]. According to the Tanzania Demographic Health Survey, the maternal mortality ratio accounts for 556 deaths per 100,000 live births while the perinatal mortality rate showed 39 deaths per 1000 pregnancies[3].

Hypertensive disorder in pregnancy is a sign of underlying pathology which appears for the first time during pregnancy and it is a common medical complication of pregnancy[4]. Hypertensive disorders of pregnancy, including preeclampsia and eclampsia, are the major health problem and the main cause of the maternal and perinatal morbidity and mortality. Tanzania, the incidence of preeclampsia and eclampsia found to be 1.7\%[5]. According to the Tanzania Demographic Health survey, it shows that hypertensive disorders in pregnancy are the second leading cause of maternal mortality which accounts for $19 \%$ of death[3]. To reduce the problem, the government set many strategies to ensure that the objectives are met. According to the Health sector strategic planning (HSSP IV) 2015- 2020 period, the following should be achieved: increasing skilled birth attendance by $80 \%$, continue to expand provision of quality services during pregnancy, childbirth, and postnatal period, provision of Basic Emergency Obstetric and Newborn care (BEmONC) and Comprehensive Emergency Obstetric and Newborn care (CEMONC), also by the end of $2020,70 \%$ of primary health facilities provide BEmONC and $50 \%$ of health centres and $100 \%$ of Hospitals provide CEMONC, also to ensure community awareness activities reach every household to achieve SDGs 4\&5[6].

There are several factors that lead to the high maternal and perinatal morbidity and mortality in the Global south such as Tanzania and the reasons are very crucial[7]. In the community perspectives, many factors involved such as knowledge gaps, myths regarding preeclampsia and eclampsia, traditional beliefs and inaccessibility of health care services during pregnancy[8]. Lack of knowledge, myths about danger signs of pregnancy makes the family not to put into considerations the early signs and symptoms of preeclampsia and eclampsia as a results delay to seek health care services [8].

So far, Men in Tanzania have inadequate knowledge regarding reproductive issues compared with Loading [MathJax]/jax/output/CommonHTML/fonts/TeX/fontdata.js rs related to family issues including health 
services utilization which bring a negative impact on the maternal and perinatal outcome[10]. Moreover, empowering men with essential information on emergency obstetric condition such as preeclampsia and eclampsia is a vital strategy towards utilization of services in reducing maternal and perinatal morbidity and mortality [11].

Previously study done in Makole Ward Dodoma Tanzania about knowledge of preeclampsia among women results revealed $41 \%$ had a low level of knowledge about preeclampsia and eclampsia, half of the respondents agreed that the disease is due to evil spirit and exposure to fire while the remaining disagreed[12]. Another study done in Same District Hospital, the results showed that only $40 \%$ had knowledge of preeclampsia while the majority (60\%) had no knowledge[13].

A study was done in Sindh Pakistan, the findings of the study revealed that preeclampsia was not recognized as a disease; however, women were aware of high blood pressure and can develop during pregnancy. Women believed that stress and weakness were conditions that cause high blood pressure and headache during pregnancy. [14].

Little is known on the knowledge and myth on pre-eclampsia and eclampsia and its influence in antenatal attendance in rural community of Tanzania.

\section{Methods}

\section{Study area}

This study was conducted in Mtwara region. The Region covers the total area of $16,710 \mathrm{~km}^{2}(6,450 \mathrm{sqmi})$. Administratively the Region divided into nine districts that are Mtwara Municipal, Newala DC, Tandhimba, Masasi DC, Nanyumbu, Masasi TC, Mtwara DC, Newala TC, and Nanyamba TC. The region has a total of 253 health facilities among those Hospitals are 6 whereby 5 public and 1 faith based organization.

Health centres are 22, public 15, FBO 2, and 5 are private. Dispensaries are 225 whereby 195 public, 13 FBOs and 17 private. Almost all facilities are providing ANC services like physical examination of pregnant women, Health education about danger signs of pregnancy, testing and counseling for HIV/AIDS, Vaccination of Tetanus toxoid, micronutrients provision and checking for Hemoglobin level etc.

Based on 2012 National population and Housing Census, the Region had a population of 1,270,854, which was lower than the Pre-census projection of 1, 374, 767 people of whom 599, 648 were male and 671,206 were female. The estimated average household size is 3.7 [15]. The majority of people depend on agricultural activities to sustain their lives. They have mainly planted cassava, sorghum, paddy and maize. Cash crops are Cashew nuts, simsim and groundnuts. But the economic status of Mtwara mainly depends on Cashew nuts.

\section{Setting}


The study involved 4 districts namely Mtwara DC, Newala, Nanyumbu, and Masasi. In each District two wards were involved, making a total of eight wards, At village level three villages from each ward were involved making a total of 24 villages.

\section{Study design}

A community based analytical cross sectional study was conducted. The study employed a quantitative research approach. This design was chosen so as to assess the community myths about preeclampsia and eclampsia towards Antenatal services utilization.

\section{Study population}

Pregnant women who were in second and third trimester with their Male partners. This group was at risk group for preeclampsia and eclampsia since the women were pregnant and were the one who expected to utilize ANC services. Furthermore male partners are the decision maker in family level even regarding the health of their spouse.

\section{Inclusion criteria}

All pregnant women including prime gravid and multigravid who were in the second and third trimester, gestation age of 24 weeks and above who lived together with their male partners who were willing to participate in the study. These groups provided valid information on their knowledge and myths about preeclampsia and eclampsia.

\section{Exclusion criteria}

Pregnant women and their partners who were very sick, mentally incapability and who refused to be involved in this study.

\section{Sample size calculation}

Since there was no any documented study done in Mtwara Region showing the prevalence of preeclampsia and eclampsia, hence, this study used a prevalence of $50 \%$ as a standard to calculate the sample size. By using the Kish Leslie formula as follows: -

\section{$\mathrm{N}=\underline{\mathrm{Z}^{2} \times \mathrm{P}(100-\mathrm{P})}$ \\ $\mathrm{E}^{2}$}

Whereby

$\mathrm{N}=$ sample size

Z= Confident interval to 95\% (1.96) 
$\mathrm{E}=$ Worst acceptable margin error (0.05)

HENCE:

$\mathrm{N}=\underline{(1.96)^{2} \times 50 / 100(100-50 / 100)}$

$(0.05)^{2}$

$\mathrm{N}=384.16$. Therefore the sample size was 384 couples.

\section{Sampling technique}

The region was selected purposively because of an increasing number of preeclampsia and eclampsia and women reported at the health facility while already had eclamptic fit as seen earlier in RCH report of 2018. Then districts, wards, and villages employed multistage sampling. The first stage was a selection of four Districts (Mtwara DC, Nanyumbu, Newala and Masasi DC) out of nine districts within Mtwara Region. Simple random sampling using the lottery method was used to select the districts. A list of all districts was obtained and the names of the districts were listed. Pieces of paper were divided according to the number of districts and the names of the district were written in each small piece of paper then each piece of paper was folded and put together in a box. Then the box was shaken and four pieces were picked at random and names of districts were identified. The second stage was a selection of wards whereby all wards in each district (21 Wards of Mtwara DC, 17 Wards of Nanyumbu district, 22 Wards of Newala district and 34 Wards of Masasi district) were listed. By using the lottery method two wards from each district were selected randomly to obtain a total of 8 wards. The third stage was selection of three villages from each selected ward by repeating the same procedure to obtain a total of 24 villages. The fourth stage was a selection of participants from each village whereby a list of pregnant women with gestation age of 24 weeks and above who lived with a male partner was obtained from a ten cell leader and eligible participants were given a number, thereafter by the use of lottery method simple random procedure was employed to select 16 expecting couples who met inclusion criteria from each village.

\section{Research instruments}

The tool used to collect data was a structured questionnaire, with closed ended questions and openended questions. The questionnaire was divided into four sections. Social-demographic and social economic characteristics, questions for measuring knowledge, myths and Antenatal service utilization.

Social demographic and social economic characteristics adapted from NBS, 2015. The questions were translated in Swahili language and the whole questionnaire took 30 minutes to complete.

\section{Data collection process.}

Data were collected through interviewer structured questionnaires. A researcher together with research assistants interviewed the eligible respondents whereby the researcher and research assistant filled the 
questionnaire the response from the participants. Ten research assistants were involved in data collection after being trained before the process commenced.

\section{Data processing and analysis}

Data obtained were coded manually and then were entered into the computer and cleaned. Data analysis was finally done by using statistical package for the social sciences (SPSS) computer software version 20. Frequencies and cross tabulations were done. Data were summarized into frequency tables, figures and chi square was done to look for an association between demographic variable and outcome variables. Logistic regressions were used to determine the strength of association between selected variables and outcome variable. Moreover, a P-value and confidence interval used to verify the significance of the differences found. A P-value $<0.05$ was considered to be statistically significant. The principal component analysis was also done to find out the weighted score of the questions asked. A weighted score of $>0.3$ was regarded as relevant.

Measurements of the variables.

Knowledge on preeclampsia and eclampsia was measured by nominal scale involved 38 items on knowledge with yes/no answers which were then converted into correct and incorrect. Then one score for each correct answer and zero score for each wrong answer (Savage \& Hoho, 2016). Principal component analysis was done to analyze knowledge. Mean was used to categorize the level of knowledge. Below the mean inadequate knowledge and above the mean Adequate knowledge.

Myths on preeclampsia /eclampsia adapted and modified from (Boene et al., 2016). This involved with 6 open ended questions regarding myths on preeclampsia and eclampsia. Difference responses were obtained from the respondents. Similar answers were grouped and then coded. Therefore myths was measured by employing principle component analysis and median was used as a cutoff point to categorize whereby those below the median had weak myths and above the median had strong myths.

Antenatal service utilization involved 7 items adapted and modified from (Doe, 2013). Utilization was measured by number of recommended antenatal visits by WHO guideline. Therefore if the women attended ANC less than two visits was graded as inadequate utilization of ANC services and if attended two or more visits graded as adequate utilization of ANC service. (Hijazi, Alyahya, Sindiani, Saqan, \& Okour, 2018).

\section{Ethical consideration}

The proposal was approved by Institutional research review board of the University of Dodoma. Furthermore, letter of permission was obtained from the Mtwara Regional Administration. Both written and verbal consents were sought from study participants after explaining the study objectives and procedures and their right to refuse to participate in the study at any time they were assured. 


\section{Results}

\section{Social- demographic characteristics of the participants.}

The study involved 384 couples who met inclusion criteria. Among them, female were 384 and male also were 384 which made a total of 768 participants. Results indicated that Majority of the participants 270 (36.0\%) were in the age group, The mean age was $31.71 \pm 8.056$, median age 30.00 , minimum age 18 and maximum age was 59. Regarding the education level of the participants, the large proportion of respondents $465(60.0 \%)$ had primary education and a small proportion $92(12.5 \%)$ had secondary education. Majority of the participants $665(84 \%)$ were peasants and those who had three or more children were 260 33.9\%). Majority of the participants 605 (78.0\%) had an income of less than 1000 T.shs per day. Large proportion 599 (78.0\%) were able to access health facility when they face problems. (Table $1)$.

Table 1: Social-demographic distribution of the participants $(\mathrm{N}=768)$

\begin{tabular}{|c|c|c|}
\hline Variable & Frequency (n) & Percentage (\%) \\
\hline \multicolumn{3}{|l|}{ Age group } \\
\hline $18-25$ & 197 & 25.0 \\
\hline $26-33$ & 270 & 36.0 \\
\hline $34-41$ & 188 & 24.0 \\
\hline $42+$ & 113 & 15.0 \\
\hline \multicolumn{3}{|l|}{ Sex } \\
\hline Male & 384 & 50.0 \\
\hline Female & 384 & 50.0 \\
\hline \multicolumn{3}{|l|}{ Education level } \\
\hline No formal education & 211 & 27.5 \\
\hline Primary & 465 & 60.5 \\
\hline Secondary & 92 & 12.5 \\
\hline \multicolumn{3}{|l|}{ Occupation } \\
\hline Employed & 16 & 2.1 \\
\hline Unemployed & 61 & 7.9 \\
\hline Self employed & 46 & 6.0 \\
\hline Peasant & 665 & 84.0 \\
\hline \multicolumn{3}{|l|}{ Religion } \\
\hline Christian & 161 & 21.0 \\
\hline Muslim & 607 & 79.0 \\
\hline \multicolumn{3}{|l|}{ Ethnicity } \\
\hline Makonde & 285 & 37.1 \\
\hline Makuwa & 335 & 43.6 \\
\hline Yan & 82. & \multirow[t]{2}{*}{10.7} \\
\hline onHTML/fonts/Te & lata.js & \\
\hline
\end{tabular}




\begin{tabular}{lll} 
Others & 66 & 8.6 \\
Number of children & & \\
One & 162 & 21.1 \\
Two & 193 & 25.1 \\
Three or more & 260 & 33.9 \\
None & 153 & 19.9 \\
Access to health facility & & \\
Yes & 599 & 78.0 \\
No & 169 & 22.0 \\
Distance to health facility & & \\
< than 5 Kilometer & 586 & 76.3 \\
>than 5 Kilometer & 182 & 23.7 \\
Daily income & & \\
<than 1000 T.shs & 605 & 21.2 \\
>than 1000 T.shs & 163 & \\
\hline
\end{tabular}

\section{Level of knowledge about preeclampsia and eclampsia among expecting couples}

The results of the analysis showed that among 768 respondents, the majority 477 (62. \%) had an inadequate level of knowledge while 291 (38\%) had adequate level of knowledge. (Figure1).

\section{Myths about preeclampsia and eclampsia among expecting couples}

The findings revealed that the majority of the participants 236 (30.7\%) reported that the local name for preeclampsia and eclampsia is the devils disease and $12(1.6 \%)$ said that it is a big illness. Majority of the participants $286(37.2 \%)$ said preeclampsia and eclampsia is due to devils living in the wild, sea and big trees while 145 (18.9\%) said that mistreatment from in-law was the cause. 191 (24.9\%) reported that the presentation of preeclampsia and eclampsia is heart burn (Kyokombe) while 139 (18.1\%) said eye rolling back. Regarding the consequence of preeclampsia and eclampsia, $392(51.0 \%)$ reported mental illness while 192 (25.0\%) reported intrauterine fetal death (Litulilye). (Table 2)

Table 2: Myths about preeclampsia and eclampsia $(\mathrm{N}=768)$

\begin{tabular}{lll}
\hline Variable & Frequency & Percentage \\
& $(\mathrm{n})$ & $(\%)$ \\
\hline
\end{tabular}


Local name for preeclampsia and eclampsia

The devil disease

Snake illness

God-made disease

Magic disease

Big illness

Homa ya mdudu

12

Illness of the moon

92

Myths regarding the cause of preeclampsia and eclampsia

Devils living in the wild, sea and big trees.

Witch craft

Mnyama (animal)

Mistreatment by in-law

$\begin{array}{ll}286 & 37.2 \\ 173 & 22.5 \\ 164 & 21.4 \\ 145 & 18.9\end{array}$

The consequence of preeclampsia \& eclampsia

Njiti (Premature baby)

Loss of memory (Kuyiwa)

11.5

Death of the mother

Mental illness

Litulilye (intrauterine fetal death)

50

Local treatment of preeclampsia and eclampsia

Drinking boiled green leaves.

Special dance to expel demons/devils

Burning leaves or incense (kufukiza ubani)

Splashing of human urine over the mother`s body with eclampsia. 


\begin{tabular}{lcc}
\hline Variable & $\begin{array}{c}\text { Frequency } \\
(\mathrm{n})\end{array}$ & $\begin{array}{l}\text { Percentage } \\
(\%)\end{array}$ \\
\hline $\begin{array}{l}\text { Local prevention of preeclampsia and eclampsia } \\
\text { Tie string of tree on the waist }\end{array}$ & 173 & 22.5 \\
Wear charms- (Hirizi) around the neck & 181 & 23.6 \\
$\begin{array}{l}\text { Wear of black clothe on the hand } \\
\text { Boil the wood of trees and bathe }\end{array}$ & 78 & 10.2 \\
Lie the pregnant mother under the bed. & & \\
& 157 & 20.4 \\
& & \\
& & \\
& & \\
\end{tabular}

\section{Level of Myths about preeclampsia and eclampsia}

The results showed that $51.6 \%$ had weak Myths and $48.4 \%$ had strong Myths about preeclampsia and eclampsia. Figure 2

\section{Antenatal care service utilization.}

The current study was also assessed ANC utilization among expecting mothers in Mtwara region $\mathrm{N}=$ 384. ANC utilization was defined as adequate if the women had at least two visits or more otherwise was inadequate keeping in mind that the current study dealt with the women who were in second and third trimester with the gestation age of 24 weeks and above together with their male partners. The total female participants were 384 and their findings regarding ANC services revealed that majority 244 (64\%) had an adequate utilization since they attended two or more visits and $140(36 \%)$ had an inadequate utilization as they attended less. Figure 3.

\section{Association between the level of knowledge and antenatal care service utilization.}

A Chi-square was done to show the relationship between knowledge and antenatal care services utilization then bivariate and Multivariate logistic regression was done. The findings showed that those who had adequate knowledge were all most 3 times more likely to utilize antenatal services compared to those who had inadequate knowledge $(A O R=2.827 ; \mathrm{Cl}=1.719,4.651 ; \mathrm{P}=0.000)$. Also those who had three or more children were 2 times more likely to utilize ANC services compared to those who had no children $(A O R=2.148 ; \mathrm{Cl}=1.030,4.483 ; \mathrm{P}=0.042)$. Other factors showed no association. More details as shown in table 3. 


\begin{tabular}{|c|c|c|c|c|c|c|c|c|}
\hline \multirow[t]{2}{*}{ vastavic } & \multirow[t]{2}{*}{ UI } & \multirow[t]{2}{*}{ I-varue } & \multicolumn{2}{|c|}{ 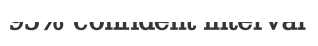 } & \multirow[t]{2}{*}{ nun } & \multirow[t]{2}{*}{ p-varue } & \multicolumn{2}{|c|}{ 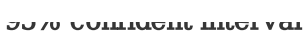 } \\
\hline & & & Lower & Upper & & & Lower & upper \\
\hline \multicolumn{9}{|l|}{ Knowledge } \\
\hline Adequate & 2.877 & 0.000 & 1.831 & 4.519 & 2.827 & 0.000 & 1.719 & 4.651 \\
\hline \multicolumn{9}{|l|}{ Inadequate(Ref) } \\
\hline \multicolumn{9}{|l|}{ Occupation } \\
\hline Employed & 0.960 & 0.963 & 0.173 & 5.322 & 0.490 & 0.480 & 0.068 & 3.547 \\
\hline Unemployed & 1.011 & 0.979 & 0.455 & 2.247 & 0.891 & 0.805 & 0.357 & 2.225 \\
\hline Self employed & 7.201 & 0.001 & 2.335 & 22.207 & 3.385 & 0.076 & 0.878 & 13.047 \\
\hline \multicolumn{9}{|l|}{ Peasant (Ref.) } \\
\hline \multicolumn{9}{|l|}{ Ethnicity } \\
\hline Makonde & 0.502 & 0.237 & 0.160 & 1.574 & 0.304 & 0.062 & 0.087 & 1.063 \\
\hline Makuwa & 0.656 & 0.464 & 0.212 & 2.030 & 0.370 & 0.122 & 0.105 & 1.306 \\
\hline Yao & 2.593 & 0.165 & 0.676 & 9.947 & 1.104 & 0.898 & 0.241 & 5.052 \\
\hline \multicolumn{9}{|l|}{ Others (Ref.) } \\
\hline \multicolumn{9}{|l|}{ Number of children } \\
\hline One & 2.595 & 0.006 & 1.317 & 5.112 & 1.712 & 0.164 & 0.802 & 3.652 \\
\hline Two & 1.665 & 0.141 & 0.845 & 3.279 & 1.315 & 0.489 & 0.606 & 2.851 \\
\hline Three or more & 2.303 & 0.010 & 1.220 & 4.350 & 2.148 & 0.042 & 1.030 & 4.483 \\
\hline \multicolumn{9}{|l|}{ None (Ref.) } \\
\hline \multicolumn{9}{|l|}{ Access to health facility } \\
\hline Yes & 0.586 & 0.033 & 0.358 & 0.957 & 2.072 & 0.353 & 0.445 & 9.637 \\
\hline \multicolumn{9}{|l|}{ No (Ref.) } \\
\hline \multicolumn{9}{|c|}{ Distance to health facility } \\
\hline Less than 5 kilometer & 0.521 & 0.007 & 0.323 & 0.840 & 0.297 & 0.113 & 0.067 & 1.330 \\
\hline \multicolumn{9}{|c|}{ More than 5 Kilometer (Ref.) } \\
\hline \multicolumn{9}{|l|}{ Wealth index } \\
\hline \multicolumn{9}{|l|}{ Poorest (Ref.) } \\
\hline hJax]/jax/output/C & ITML & onts/Te & /fontd & & & & & \\
\hline
\end{tabular}




\begin{tabular}{|c|c|c|c|c|c|c|c|c|}
\hline roor & U.b5s & $U . / 3 U$ & U.Ub४ & 1.341 & U.J4L & U.bb8 & U.U3S & 8.yu4 \\
\hline Middle & 0.759 & 0.265 & 0.467 & 1.232 & 1.092 & 0.755 & 0.628 & 1.898 \\
\hline High & 0.423 & 0.002 & 0.243 & 0.736 & 0.402 & 0.004 & 0.216 & 0.751 \\
\hline
\end{tabular}

\section{The association between myths about preeclampsia and eclampsia and antenatal care services}

\section{utilization.}

A Chi-square done to show the relationship between Myths about preeclampsia and eclampsia and antenatal care services utilization then Bivariate and Multivariate logistic regression done. The findings showed those who had weak myths were $63 \%$ less likely to utilize ANC services compared to those who had strong myths. $(A O R=0.370 ; C l=0.229,0.599 ; P=0.000)$. Furthermore, other factors showed no association. Table 4.

Table 4: Bivariate and multivariate logistic regression between myths about preeclampsia and eclampsia and ANC utilization $\mathrm{N}=384$

\begin{tabular}{|c|c|c|c|c|c|c|c|c|}
\hline \multirow[t]{2}{*}{ Variable } & \multirow[t]{2}{*}{ OR } & \multirow[t]{2}{*}{ P-value } & \multicolumn{2}{|c|}{$95 \%$ confident interval } & \multirow[t]{2}{*}{ AOR } & \multirow[t]{2}{*}{ p-value } & \multicolumn{2}{|c|}{$95 \%$ confident interval } \\
\hline & & & Lower & Upper & & & Lower & upper \\
\hline \multicolumn{9}{|l|}{ Myths } \\
\hline Weak myths & 0.424 & 0.000 & 0.277 & 0.650 & 0.370 & 0.000 & 0.229 & 0.599 \\
\hline \multicolumn{9}{|c|}{ Strong myths (Ref.) } \\
\hline \multicolumn{9}{|l|}{ Occupation } \\
\hline Employed & 0.960 & 0.963 & 0.173 & 5.322 & 0.495 & 0.499 & 0.064 & 3.807 \\
\hline Unemployed & 1.011 & 0.979 & 0.455 & 2.247 & 0.696 & 0.435 & 0.279 & 1.732 \\
\hline Self employed & 7.201 & 0.001 & 2.335 & 22.207 & 3.816 & 0.050 & 1.002 & 14.533 \\
\hline \multicolumn{9}{|l|}{ Peasant (Ref.) } \\
\hline \multicolumn{9}{|l|}{ Ethnicity } \\
\hline Makonde & 0.502 & 0.237 & 0.160 & 1.574 & 0.346 & 0.100 & 0.098 & 1.225 \\
\hline Makuwa & 0.656 & 0.464 & 0.212 & 2.030 & 0.411 & 0.169 & 0.116 & 1.460 \\
\hline Yao & 2.593 & 0.165 & 0.676 & 9.947 & 1.467 & 0.620 & 0.323 & 6.660 \\
\hline \multicolumn{9}{|l|}{ Others (Ref.) } \\
\hline \multicolumn{9}{|c|}{ Number of children } \\
\hline One & 2.595 & 0.006 & 1.317 & 5.112 & 1.540 & 0.258 & 0.729 & 3.254 \\
\hline
\end{tabular}




\begin{tabular}{|c|c|c|c|c|c|c|c|c|}
\hline Two & 1.665 & 0.141 & 0.845 & 3.279 & 1.214 & 0.622 & 0.562 & 2.623 \\
\hline Three or more & 2.303 & 0.010 & 1.220 & 4.350 & 1.772 & 0.125 & 0.853 & 3.680 \\
\hline \multicolumn{9}{|l|}{ None (Ref.) } \\
\hline \multicolumn{9}{|l|}{ Access to health facility } \\
\hline Yes & 0.586 & 0.033 & 0.358 & 0.957 & 1.955 & 0.394 & 0.418 & 9.139 \\
\hline \multicolumn{9}{|l|}{ No (Ref.) } \\
\hline \multicolumn{9}{|c|}{ Distance to health facility } \\
\hline Less than 5 kilometer & 0.521 & 0.007 & 0.323 & 0.840 & 0.291 & 0.108 & 0.065 & 1.310 \\
\hline \multicolumn{9}{|c|}{ More than 5 Kilometer (Ref.) } \\
\hline \multicolumn{9}{|l|}{ Wealth index } \\
\hline \multicolumn{9}{|l|}{ Poorest (Ref.) } \\
\hline Poor & 0.653 & 0.730 & 0.058 & 7.341 & 0.407 & 0.539 & 0.023 & 7.185 \\
\hline Middle & 0.759 & 0.265 & 0.467 & 1.232 & 0.963 & 0.893 & 0.556 & 1.669 \\
\hline High & 0.423 & 0.002 & 0.243 & 0.736 & 0.361 & 0.001 & 0.194 & 0.672 \\
\hline
\end{tabular}

\section{Discussion}

The results of the current study showed that $62.1 \%$ had inadequate knowledge about preeclampsia and eclampsia. The results of this study differ with the findings of previous work done in Makole Dodoma ${ }_{12}$ ]which revealed that $41 \%$ of the respondents had low knowledge. This difference might be due to the geographical location where study was conducted as the current study conducted in Rural while the previous conducted in Urban, also it could be due to the differences in study population as the current study dealt with expecting couples both pregnant women and their male partners while the previous study focused mainly on pregnant women. This finding is in agreement with $\left[_{13}\right]$ findings which showed $60.0 \%$ of the respondents reported to have no knowledge.

The findings of the present study showed that those who had adequate knowledge about preeclampsia and eclampsia were $37.9 \%$. The present findings seem to be inconsistent with other research done in Same Moshi Tanzania ${ }_{13}$ ]which found that $40 \%$ reported having adequate knowledge on preeclampsia and eclampsia [16].. The findings might be due to the unplanned or absence of educational program regarding preeclampsia and eclampsia in the health facility as well as Community bases. 
Following the present results, previous studies have demonstrated that the local name was Rtjhodabaovadhan meaning that high blood pressure [ $\left.{ }_{14}\right]$. Another study was done in Southern Mozambique [17 ] reported that the local name for preeclampsia and eclampsia were falling disease, fainting disease, snake illness or childhood illness. This inconsistency of the findings might be due to the different study area and social demographic characteristics of the participants. Regarding the causes, the current study $37.2 \%$ of the participants reported that the cause was the devil living in the wild, sea, and big trees and $22.5 \%$ reported to be caused by frequency fever. These findings differ from the previous study [17 ]who reported the causes were mistreatment by in-laws, marital problems, and excessive thinking or worrying. These differences might be due to the cultural differences of the participants. Another important finding was that $10.5 \%$ of the respondents from the current study reported dizziness and Convulsions (kukwijula) were the signs and symptoms of preeclampsia and eclampsia. This is in line with the previous study [14] who reported the same findings. Drinking boiled green leaves was the local treatment of preeclampsia and eclampsia reported in the present study which accounts for $37.4 \%$ of the participants, special dance to expel demons/devils $24.7 \%$, burning leaves or incense (ubani) $18.9 \%$. These findings compared by the previous study [18]which showed that traditional treatment of preeclampsia were eating onions, drinking solution of the salt, bodily incisions and prayers. Another study [14] reported that the use of home remedies, spiritual treatment and alternative medicine. These findings imply that local treatment differs regarding culture, ethnicity and beliefs though there are some in common.

Antenatal care utilization among expecting mothers who were in second and third trimester starting gestation age of 24 weeks and above. The results of the current study $64 \%$ of the expecting mothers had adequate antenatal care service utilization. These results agree with the findings of other study done in Jordan ${ }_{19}$ ] in which $63.4 \%$ of the respondents had adequate ANC service utilization. It seems possible that these results might be due to an increasing number of health facilities in each village also the effort done by the government to ensure that every pregnant woman should be attended by the trained personnel as well as free services offered to pregnant women. A similar study was done Eastern Napel [20] which showed that $69 \%$ of the participants had higher antenatal care service utilization. Furthermore, the current study indicated that those who had inadequate ANC service utilization were $36 \%$. These results differ from the study done in Geita Tanzania [21] which showed the extremely low ANC attendance by $3.62 \%$. This inconsistency might be due to the social cultural beliefs, lack of knowledge regarding the importance of ANC utilization. It might be also the nature of the participants regarding their activities as the majority of the participants in Geita engaged in animal keeping and they tends to move from one place to another to fetch food for their animals. Therefore, this might be the reason for inadequate ANC utilization.

The current study determine the association between knowledge of preeclampsia and eclampsia towards ANC utilization which showed statistically significant association whereby those who had adequate knowledge about preeclampsia and eclampsia were 3 times more likely to utilize antenatal care service compared to those who had inadequate knowledge $(P-v a l u e<0.05)$. Different from the study done in Napel [20] which showed that those respondents who had knowledge were 5 times more Loading [MathJax]/jax/output/CommonHTML/fonts/TeX/fontdata.js 
likely to have antenatal care utilization compared to those who did not have knowledge. These findings seemed to have difference since the current study was conducted in a developing country where the majority of their people had a primary level of education and were not much exposed to social media where can search information compared to the previous study which was conducted in a developed country. Therefore, women should be equipped with knowledge regarding their health and this could facilitate them to utilize antenatal care services.

The findings showed that those who had weak myths were less likely to utilize ANC services compared to those who had strong myths $(P=0.000)$. These findings differ from the previous study [20] which showed that those who believed from traditional healers were less likely to have antenatal care service utilization than those who did not believe tradition healers. These inconsistency results might be due to lack of adequate knowledge about preeclampsia and eclampsia though the participants had weak myths also resistance in behavior change. It might be also they did not see any benefit obtained through utilizing antenatal services. Furthermore, although the present study showed a number of respondents who had strong myths are a bite low but still more effort is needed to dispel myths and misconceptions in the community at large and ensure all pregnant women are utilizing antenatal services for the benefit of both mother and unborn baby.

\section{Conclusion}

The overall knowledge about preeclampsia and eclampsia was low. Majority of the participants had weak myths although the different with those who had strong myths was small. The majority of the expecting mothers utilized antenatal care services. Furthermore, findings showed that those who adequate knowledge had adequate antenatal services utilization. Moreover, those who had strong myths found to have antenatal care services utilization. Therefore, the community should be educated regarding the facts about preeclampsia and eclampsia in order to dispel the available Myths and misconceptions and ensure ANC services utilization for all pregnant women.

\section{Limitations}

This study conducted in Mtwara region involved four district and it was about knowledge and myths regarding preeclampsia and eclampsia therefore it might not reflect the whole country due to cultural diversity as in every region have their own myths and cultural differences.

\section{List Of Abbreviations}

ANC-Antenatal clinic, AIDS - Acquired Immuno Deficiency Syndrome, BEmONC - Basic Emergency Obstetric and Newborn Care., CEMONC - Comprehensive Emergency Obstetric and Newborn Care., DCDistrict council, HBM- Health belief model, HELLP - Hemolysis, Eleveted Liver enzyme, Low Platelet count., H/F- Health facility, HSSP - Health Sector Strategic Plan, MDGs - Millennium Development Goals, 
Reproductive and Child Health., SPSS - Statistical Package for Social Sciences, TDHS - Tanzania Demographic Health Survey, TC- Town council, UDOM - University of Dodoma, URT - United Republic of Tanzania, UNFPA - United Nation Fund for Population Activities, UNICEF- United Nation International Children emergence Fund, USA - United State of America, WHO - World Health Organization

\section{Declarations}

\section{Acknowledgements}

My sincere gratitude goes to the University of Dodoma, Regional administrative secretary of Mtwara region, Districts administrative secretaries of Mtwara DC, Newala, Nanyumbu and Masasi DC, all Districts executives' directors (DED), Ward Executive officers (WEO) and Village leaders who granted me a permission to conduct this study in their respective areas. I would also like to extend my deep appreciation and sincere gratitude to my supervisors, my research assistants, and the study participants for their willingness to participate in this study. I would also wishes to thank Dr. Secilia K. Ng weshemi and Dr. Julius Ntwenya for support and encouragement throughout the course of this study.

\section{Funding}

There was no external source of funding used for this study.

\section{Availability of data and materials}

The dataset used and /or analyzed during the current study are available from corresponding author on reasonable request.

\section{Author's contributions}

SMK senior supervisor assisted in data analysis, NG, FM and AL contributed to the interpretation of data. All authors read, commented on and approved the final manuscript.

\section{Ethical approval and consent to participate}

Ethical clearance was obtained from University of Dodoma ethics and committee before commencing the data collection. Also permission to conduct the study obtained from the Regional administrative secretary of Mtwara, District Administrative secretaries of Mtwara District council, Newala, Nanyumbu and Masasi DC. The permission letters obtained were presented to Ward Executive officers, and Village leaders who granted me a permission to conduct study in their respective areas. Written consent was obtained from each participant before data collection.

\section{Consent for publication}

Not applicable 


\section{Competing of interests}

The author declares that there was no conflict of interest.

\section{Author details}

${ }^{1}$ Department of clinical Nursing- Division of Nursing and Midwifery services Ministry of health community development, Gender, Elderly and Children Box 743, Dodoma Tanzania. ${ }^{2}$ Acting Depute Principal Collage of Health Science, University of Dodoma Box 295 Dodoma Tanzania, ${ }^{3}$ Department of Public Health, University of Dodoma Box295 Dodoma Tanzania, ${ }^{4}$ Department of health services, University of Dodoma Box 295 Dodoma Tanzania and ${ }^{5}$ Department of Nursing and Midwifery, University of Dodoma Box 295 Dodoma Tanzania.

\section{References}

1. WHO, UNICEF, UNFPA, The World Bank UN. Trends in Maternal Mortality: 1990 to 2013;; 2014.

2. WHO UNICEF, UNFPA WBG and the UN, Division P. Trends in maternal mortality: 1990 to 2015. 2015.

3. TDHS. Demographic and Health Survey and Malaria Indicator Survey.; 2015.

4. Konar H. DC Dutta's Textbook of Obstetrics. 8th editio. New Delhi London: Jaypee Brothers Medical Publisher (P) Ltd; 2015.

5. Ajah L, Ozonu N, Ezeonu P, Lawani L, Obuna J, Onwe E. The feto-maternal outcome of preeclampsia with severe features and eclampsia. J Clin Diagn Res. 2016.

6. MOHsw. Health Sector Strategic Plan July 2015-June 2020.; 2015.

7. WHO. Maternal mortality [Internet]. Available from http//www.who.int/mediacentre/factsheets/fs348/en/. 2016.

8. Ogunjimi L, Ibe T, Ikorok M. Curbing maternal and child mortality. Int J Nurs midwifery. 2012;4(33-9).

9. Iliyasu Z, Abubakar I, Galadanci H, Aliyu M. Birth preparedness, complication readiness and fathers' participation in maternity care in a northern Nigerian community. Afr J Reprod Heal. 2010;14(1):2132.

10. Bhatta D. Involvement of males in antenatal care, birth preparedness, exclusive breast feeding and immunizations for children in Kathmandu, Nepal. BMC Pregnancy Childbirth. 2013.

11. Nanjala M, Wamalwa D. Determinants of Male Partner Involvement in Promoting Deliveries by Skilled Attendants in Busia, Kenya. Glob J Heal. 2012.

12. Savage AR, Hoho L. Knowledge of pre-eclampsia in women living in Makole Ward, Dodoma, Tanzania . 2016;16(2):412-419.

13. Eze ED, Barasa A, Adams MD, Rabiu KM, Sulaiman SO, Ponsiano N. Determination , knowledge and prevalence of pregnancy-induced hypertension / eclampsia among women of childbearing age at Same District Hospital in Tanzania. 2018;10(February):19-26. doi:10.5897/IJMMS2017.1343 
14. Khowaja AR, Qureshi RN, Sheikh S, et al. Community 's perceptions of pre-eclampsia and eclampsia in Sindh Pakistan: a qualitative study. Reprod Health. 2016;13(Suppl 1). doi:10.1186/s12978-0160136-x

15. URT. 2012 POPULATION AND HOUSING CENSUS. National Bureau of Statistics Microfinance Dar Es Salaam and Office of Chief Government Statistician President's Office, Finance, Economy and Development Planning Zanzibar.; 2013.

16. Zuo tey chiao, Teng see poh, Keng soon lean, Jummaat fauziah bt. Knowledge of preeclampsia among antenatal women in atertiary referral teaching hospital. Malaysian J Nurs. 2016;7(2):8-13.

17. Boene $\mathrm{H}$, Vidler M, Sacoor $\mathrm{C}$, et al. Community perceptions of pre-eclampsia and eclampsia in southern Mozambique. Reprod Health. 2016;13(Suppl 1). doi:10.1186/s12978-016-0135-y

18. Akeju DO, Vidler M, Oladapo OT, Sawchuck D, Qureshi R, Dadelszen P Von. Community perceptions of pre-eclampsia and eclampsia in Ogun State, Nigeria : a qualitative study. Reprod Health. 2016;13(Suppl 1). doi:10.1186/s12978-016-0134-z

19. Hijazi HH, Alyahya MS, Sindiani AM, Saqan RS, Okour AM. Determinants of antenatal care attendance among women residing in highly disadvantaged communities in northern Jordan: a cross-sectional study. 2018:1-18.

20. Deo KK, Paudel YR, Khatri RB, et al. Barriers to utilization of antenatal care services in eastern nepal. 2015;3(August):1-7. doi:10.3389/fpubh.2015.00197

21. Konje ET, Tito M, Magoma N, et al. Missed opportunities in antenatal care for improving the health of pregnant women and newborns in Geita district, Northwest Tanzania. 2018:1-13.

\section{Figures}




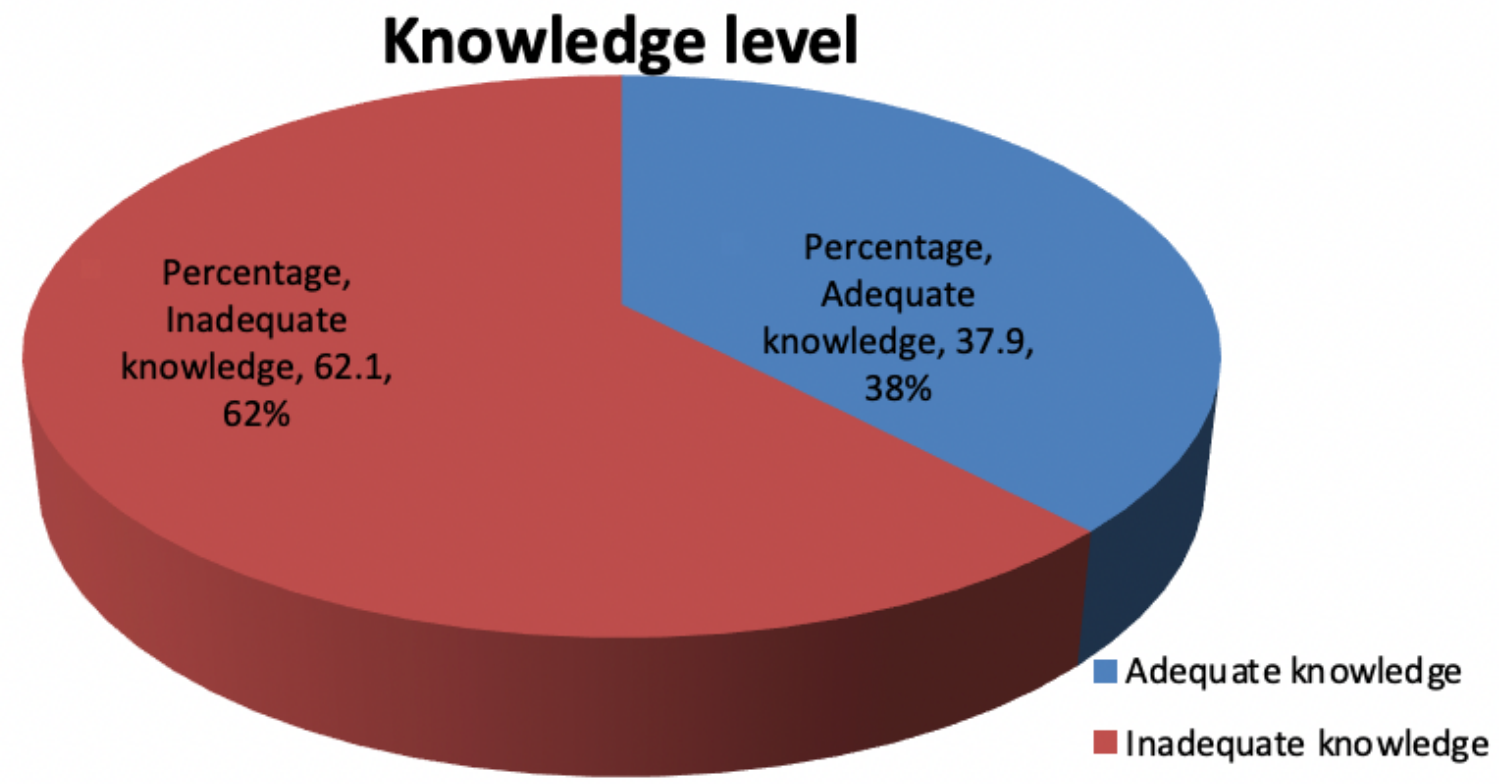

Figure 1

Level of knowledge about preeclampsia and eclampsia among expecting couples

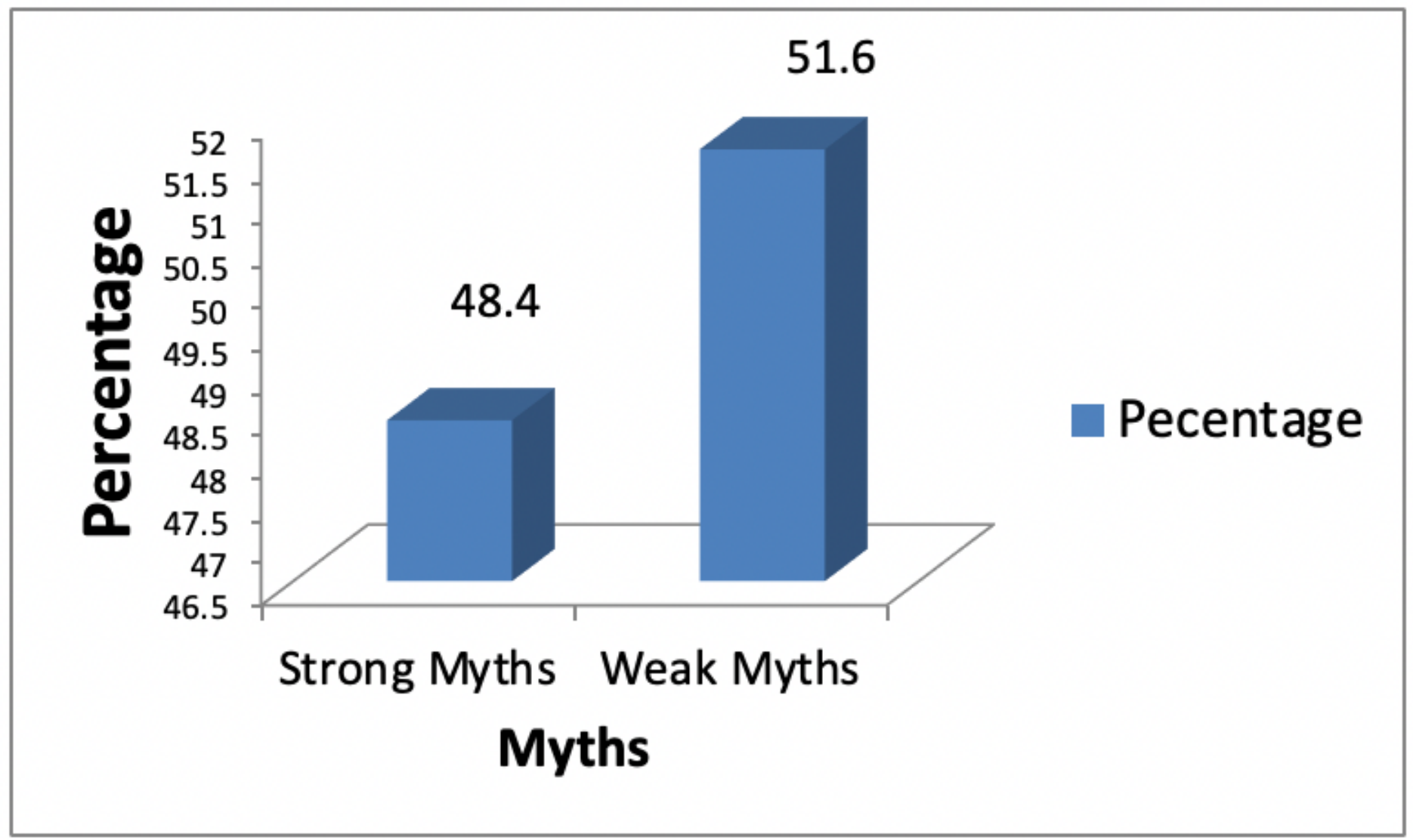


Figure 2

Categories of myths.

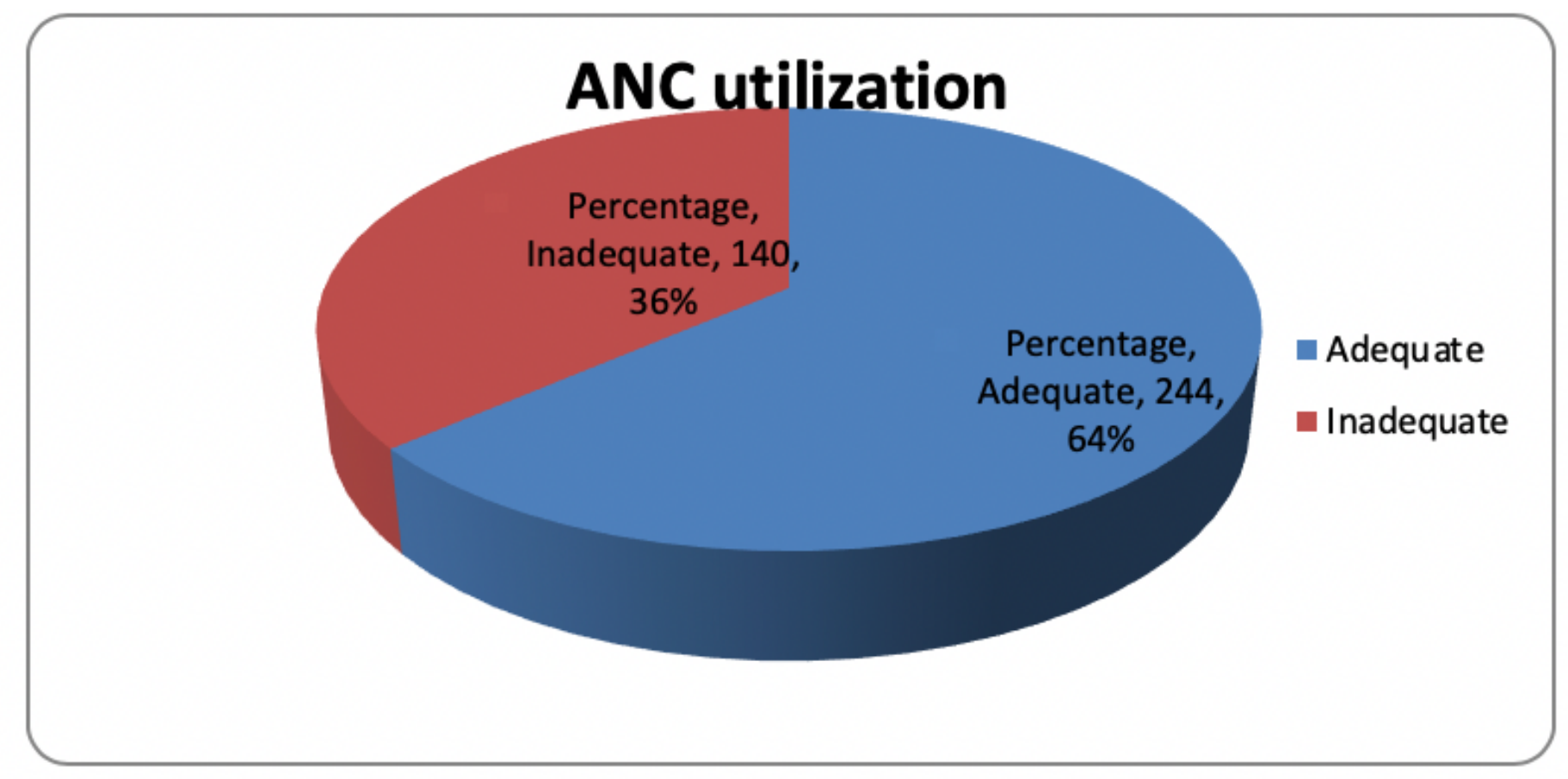

Figure 3

Antenatal care service utilization. 